\title{
Temporal Lobe Surgery for Epilepsy: Neuropsychological Variables Related to Surgical Outcome
}

\author{
Gabriel Leonard
}

\begin{abstract}
A retrospective study of 383 patients who had undergone either left or right anterior temporal lobectomy (varying with respect to the amount of hippocampus excised) revealed that there were no significant differences in surgical outcome between those patients having a large and those patients having a small hippocampal removal. Although left temporal-lobe excisions were significantly smaller than right temporal-lobe excisions, both medially and laterally, patients with left temporal-lobe removals had an overall better surgical outcome. Patients in the successful surgicaloutcome group did better than the unsuccessful surgical-outcome group on a variety of cognitive measures, including tests of intelligence, delayed verbal memory, and verbal fluency. The results suggest that, for many patients with medically intractable epilepsy, an anterior temporal lobectomy including the amygdala may suffice to reduce their seizure frequency.
\end{abstract}

\begin{abstract}
RÉSUMÉ: Chirurgie temporale dans l'épilepsie: les variables neuropsychologiques en relation avec l'issue chirurgicale. Une étude rétrospective réalisée sur 383 patients ayant subi une lobectomie temporale droite ou gauche (variant dans l'étendue de l'excision de l'hippocampe) a montré qu'il n'y avait pas de différence significative entre l'issue chirurgicale chez les patients porteurs d'une petite ou une grande résection de l'hippocampe. Bien que les excisions latérales et/ou médianes du lobe temporal gauche soient significativement plus petites que celles du lobe temporal droit, les patients qui ont subi une lobectomie temporale gauche ont, en général, obtenu de meilleurs résultats chirurgicaux. Le groupe de patients ayant un bon succès chirurgical a démontré un meilleur rendement sur une variété de mesures cognitives, y compris les tests d'intelligence, de mémoire verbale après délai et de fluence verbale, que le groupe des patient ayant une réussite chirurgicale moins grande. Les résultats suggèrent qu'une résection de la partie antérieure du lobe temporal, incluant l'amygdale, semble être suffisante pour réduire la fréquence des crises chez de nombreux patients qui présentent une épilepsie rebelle à une thérapeutique médicale.
\end{abstract}

Can. J. Neurol.Sci. 1991; 18: 593-597

Unilateral temporal-lobe surgery for epilepsy has a long record at the Montreal Neurological Hospital (MNH) and, thanks to Penfield's pioneering work, ${ }^{1}$ many more centres around the world are now providing this option for patients with medically intractable epilepsy. The surgical procedure as practised in different institutions varies greatly, and ranges from small anterior temporal neocorticectomies ${ }^{2}$ to radical temporallobe removals that include the amygdala and the bulk of the hippocampus. ${ }^{3} \mathrm{~A}$ striking feature of these procedures is that the success rate, in terms of seizure outcome, is remarkably similar from institution to institution, irrespective of the particular procedure employed.4-7 The surgical series of Drs. Theodore Rasmussen and William Feindel constitutes an ideal population in which to study the effects of the medial extent of removal on seizure outcome, as well as providing an opportunity to examine the effects of successful versus unsuccessful surgical outcome on cognitive function.

\section{SubJECTS}

Three hundred and eighty-three patients who had undergone a unilateral cortical excision at the MNH, either on $\mathrm{Dr}$. Rasmussen's service or on Dr. Feindel's service, between the years 1961 and 1980 made up the initial sample. Patients who had had preoperative independent electrographic abnormality arising from both hemispheres, or who had tumours or diffuse cerebral damage, were not included. Those patients who had had a second surgical procedure were also not considered. The operations were carried out for the relief of focal cerebral seizures, and in most instances the epileptogenic lesion dated from birth or early life, and was static in nature.

Only patients between the ages of 16 and 60 with Full-Scale Wechsler IQ's above 75 were included in the analyses. Sixty subjects were excluded because of incomplete psychological test profiles, and of the remaining 278 patients, 166 had pre- 
operative, postoperative and follow-up neuropsychological evaluations.

The 278 subjects were subdivided, according to Rasmussen's and Feindel's classification system (this supplement), into three hippocampal groups: 1) hippocampus spared or only a few millimetres of the pes excised $(n=86) ; 2)$ pes hippocampus excised plus a few millimetres of the body $(n=131)$; and 3$)$ pes plus at least half of the body excised $(n=61)$. A preliminary analysis (see Table 1) was undertaken in order to determine if there was a relationship between size of hippocampal removal and surgical outcome $(0=$ seizure free; $1=a$ few attacks during the early postoperative months or years; 2 = recurrence of one or more attacks after a seizure free period of three years; $3=$ no more than 2 attacks per year over the follow-up period; $4=$ a lesser reduction in seizure tendency). As shown in Table 1, a Chisquare test revealed no statistically significant differences with respect to surgical outcome and the extent of hippocampal excision. This fact is also made clear in the Rasmussen and Feindel reports.

For the analyses of the cognitive data, 20 patients known to have right-sided, or bilateral, speech representation (as demonstrated by preoperative intracarotid Amytal tests ${ }^{8}$ ) were eliminated, leaving a sample of 258 subjects who had had either the left or the right anterior temporal neocortex, amygdala, and varying amounts of the hippocampus excised. These subjects were then subdivided on the basis of side and of extent of removal from the hippocampus and/or the parahippocampal gyrus. The size of the hippocampal removal was considered important because the kind and extent of memory deficits observed after anterior temporal lobectomy can be exacerbated by ${ }^{9.11}$ or contingent upon the inclusion of the hippocampus in the removal.12-14 Subjects were assigned to four groups: two left temporal, one (LTh, $n=88$ ) with small and one (LTH, $n=42$ ) with large removals from the hippocampal region, and two right temporal-lobe groups, one $(\mathrm{RTh}, \mathrm{n}=65$ ) with small and one (RTH, $\mathrm{n}=63$ ) with large hippocampal excisions. The hippocampal removals were classified as small or large on the basis of the surgeon's drawing and report at the time of operation. The removal was considered to be small if no encroachment was made upon the hippocampus or if no more than the pes $(1.5 \mathrm{~cm})$ of the hippocampus was excised; the hippocampal removals were classified as large if the excision encroached further upon the body of the hippocampus or the parahippocampal gyrus. Table 2 shows the number of patients in each of the temporal-

Table 1: Seizure Outcome as Related to Extent of Hippocampal Removal

\begin{tabular}{lrrrrr}
\hline \hline & \multicolumn{5}{c}{ Seizure Outcome } \\
Hippocampal Removal & \multicolumn{1}{c}{ 0 } & $\mathbf{1}$ & $\mathbf{2}$ & $\mathbf{3}$ & $\mathbf{4}$ \\
\hline Hippocampus spared or & 19 & 18 & 17 & 7 & 25 \\
$\quad$ only mm of the Pes & $22 \%$ & $21 \%$ & $20 \%$ & $8 \%$ & $29 \%$ \\
Pes plus mm of body & 36 & 20 & 17 & 18 & 40 \\
& $27 \%$ & $15 \%$ & $13 \%$ & $14 \%$ & $31 \%$ \\
Pes plus at least half & 15 & 7 & 14 & 5 & 20 \\
of body & $25 \%$ & $11 \%$ & $23 \%$ & $8 \%$ & $33 \%$ \\
\hline
\end{tabular}

$X^{2}=7.72$, df $=8, p=.46$. lobe groups, the mean age at operation, and the mean number of years of education.

\section{Neuropsychological Measures Employed}

For the analyses of the neuropsychological data, only those tests that had been administered since the beginning of the present series (1961-1980) were included. Most subjects completed the following tests: Wechsler-Bellevue Intelligence Scale; Wechsler Memory Scale, including immediate and delayed recall measures; Wisconsin Card Sorting; Chicago Word Fluency; Chapman-Cook Speed of Reading; Copy and Delayed recall or the Rey-Osterreith Complex Figure; Wingfield Object Naming.

\section{Results}

The mean extent of the removal along the Sylvian fissure and along the base is shown in Table 3 (the discrepancy between the population numbers in Tables 2 and 3 is present because measurements were not available for all patients). We note that the lateral extent of the removals for both the Sylvian fissure and the base are almost $1 \mathrm{~cm}$ smaller on the left, and this difference

Table 2: Main Subject Groups

\begin{tabular}{|c|c|c|c|c|}
\hline \multirow[b]{2}{*}{ Group } & \multirow[b]{2}{*}{$\mathbf{N}$} & \multicolumn{2}{|c|}{$\begin{array}{c}\text { Age (years) } \\
\text { at operation }\end{array}$} & \multirow{2}{*}{$\begin{array}{c}\text { Education } \\
\text { (years) } \\
\text { Mean }\end{array}$} \\
\hline & & Mean & Range & \\
\hline \multicolumn{5}{|l|}{ Left Temporal } \\
\hline $\begin{array}{l}\text { - small hippocampal } \\
\text { removal }\end{array}$ & 88 & 31.8 & $17-45$ & 11 \\
\hline \multicolumn{5}{|l|}{ Left Temporal } \\
\hline $\begin{array}{l}\text { - large hippocampal } \\
\text { removal }\end{array}$ & 42 & 32.4 & $21-45$ & 11 \\
\hline \multicolumn{5}{|l|}{ Right Temporal } \\
\hline $\begin{array}{l}\text { - small hippocampal } \\
\text { removal }\end{array}$ & 65 & 27.7 & $17-45$ & 11 \\
\hline \multicolumn{5}{|l|}{ Right Temporal } \\
\hline $\begin{array}{l}\text { - large hippocampal } \\
\text { removal }\end{array}$ & 63 & 28.6 & $17-37$ & 11 \\
\hline
\end{tabular}

$\mathrm{N}=258 ;$ Men $=145$, Women $=113$.

Table 3: Lateral Extent of Temporal-Lobe Excisions

\begin{tabular}{|c|c|c|c|c|c|}
\hline \multirow[b]{2}{*}{ Group } & \multirow[b]{2}{*}{$\mathbf{N}$} & \multicolumn{2}{|c|}{ Sylvian Fissure } & \multicolumn{2}{|c|}{ Base } \\
\hline & & Mean & $\overline{\text { sd }}$ & $\overline{\text { Mean }}$ & sd \\
\hline \multicolumn{6}{|l|}{ Left Temporal } \\
\hline $\begin{array}{l}\text { - small hippocampal } \\
\text { removal }\end{array}$ & 62 & 5.0 & 0.7 & 5.4 & 1.0 \\
\hline \multicolumn{6}{|l|}{ Left Temporal } \\
\hline $\begin{array}{l}\text { - large hippocampal } \\
\text { removal }\end{array}$ & 32 & 4.9 & 0.6 & 5.7 & 1.1 \\
\hline \multicolumn{6}{|l|}{ Right Temporal } \\
\hline $\begin{array}{l}\text { - small hippocampal } \\
\text { removal }\end{array}$ & 45 & 5.7 & 0.7 & 6.3 & 0.9 \\
\hline Right Temporal & & & & & \\
\hline $\begin{array}{l}\text { - large hippocampal } \\
\text { removal }\end{array}$ & 49 & 6.0 & 1.2 & 6.4 & 1.1 \\
\hline
\end{tabular}


is highly significant $(\mathrm{F}=44.16$, $\mathrm{df}=1,184, \mathrm{p}<.001)$. In addition, significantly fewer large hippocampal removals were performed on the left than on the right (see Table 4) and it is therefore surprising, that left temporal lobectomy is associated with a small but significantly better chance of being in the success group (see Table 5). It is possible that a bias exists in the selection of patients for left temporal-lobe surgery, in that surgeons may prefer that these patients have preoperative medical profiles that are consistent with well lateralized and localized lesions, because they are operating on the dominant hemisphere.

\section{Analyses of Neuropsychological Measures}

Each of the neuropsychological variables was examined in the context of a 4-way analysis of variance (Side of Surgery $x$ Time of Testing $\times$ Size of Hippocampal Removal $\times$ Surgical Outcome). The Surgical-Outcome factor combined groups 1, 2, and 3 into a success group $(n=166)$, and group 4 was labelled as an unsuccessful group $(n=46)$. For the analyses, only those patients who had had a follow-up neuropsychological examination were included and thus the populations are smaller than for surgical outcome. The extent of removal from the hippocampus did not have an effect on any of the cognitive measures examined. It is noted that tests designed to be sensitive to hippocampal function were developed only after this series was begun. 12-14

Wechsler Full-Scale IQ A two-way interaction was found for Full-Scale IQ between time of testing and side of surgery ( $F$ $=6.18, \mathrm{df}=2,324, \mathrm{p}<.002$ ), and between surgical outcome and time of testing ( $f=6.04, \mathrm{df}=2,324$ ). Examination of these interactions revealed that preoperatively there were no differences between the left and right temporal-lobe groups, whereas post-operatively the LT group showed a significant decrease compared to the RT group (see Table 6). In follow-up testing, both groups improved, but the differences between the LT and RT groups was again significant. From the standpoint of surgical outcome (collapsed across side of surgery and size of hip-

Table 4: Size of Hippocampal Removal as Related to Side of Surgery

\begin{tabular}{|c|c|c|}
\hline \multirow[b]{2}{*}{ Side of Surgery } & \multicolumn{2}{|c|}{ Hippocampal removal } \\
\hline & Small & Large \\
\hline $\begin{array}{l}\text { Left temporal } \\
(n=130)\end{array}$ & $\begin{array}{r}88 \\
68 \%\end{array}$ & $\begin{array}{r}42 \\
32 \%\end{array}$ \\
\hline $\begin{array}{l}\text { Right temporal } \\
(n=128)\end{array}$ & $\begin{array}{r}65 \\
51 \%\end{array}$ & $\begin{array}{r}63 \\
49 \%\end{array}$ \\
\hline
\end{tabular}

$X^{2}=6.95, \mathrm{df}=1, p<.01$.

Table 5: Seizure Outcome as Related to Side of Surgery

\begin{tabular}{lcrr}
\hline \hline \multirow{2}{*}{ Side of Surgery } & $\mathbf{N}$ & \multicolumn{2}{c}{ Outcome } \\
\hline \multirow{2}{*}{ Left temporal } & \multirow{2}{*}{130} & 98 & 32 \\
& & $75 \%$ & $25 \%$ \\
Right temporal & \multirow{2}{*}{128} & 82 & 46 \\
& & $64 \%$ & $36 \%$ \\
\hline
\end{tabular}

$\mathrm{X}^{2}=3.92, \mathrm{df}=1, \mathrm{p}<.05$ pocampal removal), there were no significant differences in IQ preoperatively between the successful and the unsuccessful groups. Post-operatively, both groups showed a slight drop; however, in follow-up testing the patients in the successful-outcome group demonstrated a significant increase in mean IQ, which rose to 111 , whereas the unsuccessful group returned only to their preoperative level $(\mathrm{F}=5.43, \mathrm{df}=2,324, \mathrm{p}<.005)$.

Wechsler Verbal IQ The results for Verbal IQ were remarkably similar to those for Full Scale IQ, in that once again there was a two-way interaction between side of surgery and time of testing ( $F=10.27, \mathrm{df}=2,324, \mathrm{p}<.001)$ and between surgical outcome and time of testing $(F=3.31, \mathrm{df}=2,324, \mathrm{p}<.04)$. The RT group showed little change from preoperative to post-operative testing, although they demonstrated a significant improvement in follow-up (see Table 6). The LT group showed a sharp decrease post-operatively and returned just to their preoperative level in follow-up. Again the difference between the RT and LT groups in follow-up testing was significant. When the results were collapsed across group and looked at in terms of surgical outcome, the patients in the successful and the unsuccessful groups both dropped slightly post-operatively but the successful group showed a significant rise in follow-up testing.

Wechsler Performance IQ For Performance IQ there was no interaction between side of surgery and time of testing; however, the interaction between surgical outcome and time of testing was significant $(F=5.50, \mathrm{df}=2,324, \mathrm{p}<.004)$. Figure 1 illustrates this interaction, and the most salient effect is the increase in Performance IQ shown by the successful outcome group in follow-up testing.

Delayed verbal-memory index Analysis of delayed verbalmemory ability (a score composed of the mean of the delayed recall of the two Wechsler Memory prose passages plus the total number of Wechsler paired associates recalled after one and a half hours ${ }^{10}$ ) yielded a three-way interaction between side of surgery, surgical outcome, and time of testing. Figure 2 illustrates this interaction, and Tukey's post hoc tests 15 revealed that both LT groups had a significant loss post-operatively; however, in follow-up testing the successful LT group obtained significantly better recall scores than the unsuccessful LT group. As expected, neither of the RT groups showed a deleterious effect of the surgical procedure on this measure.9,11.16,17

Chicago word fluency test This test requires subjects to produce as many words as they can beginning with the letter $S$ in

Table 6: Mean Wechsler Intelligence Ratings

\begin{tabular}{lccc}
\hline \hline & \multicolumn{3}{c}{ Intelligence Quotient } \\
Side of Surgery & Full-Scale & Verbal & Performance \\
\hline Left temporal & & & \\
$\quad$ pre-op & 105 & 105 & 105 \\
post-op & 98 & 95 & 101 \\
$\quad$ follow-up & 108 & 105 & 111 \\
Right temporal & & & \\
pre-op & 105 & 106 & 103 \\
post-op & 102 & 105 & 98 \\
follow-up & 111 & 110 & 110 \\
\hline
\end{tabular}


five minutes and as many four-letter words beginning with the letter $\mathrm{C}$ in four minutes. A three way interaction was found on the $\mathrm{C}$-words between side of surgery, surgical outcome, and time of testing $(F=3.02, \mathrm{df}=2,320, \mathrm{p}<.05)$, and this is illustrated in Figure 3. Preoperatively there were no significant group differences; postoperatively the LT groups were worse than the RT groups, and in follow-up testing the patients in the unsuccessful LT group remained low, whereas the mean score for the subjects in the successful group improved significantly.

Other cognitive measures On the Wisconsin Card Sorting test there was no difference between the successful and the unsuccessful groups, and this was also true for the Chapman Cook speed of reading test, and for the Wingfield object naming test.

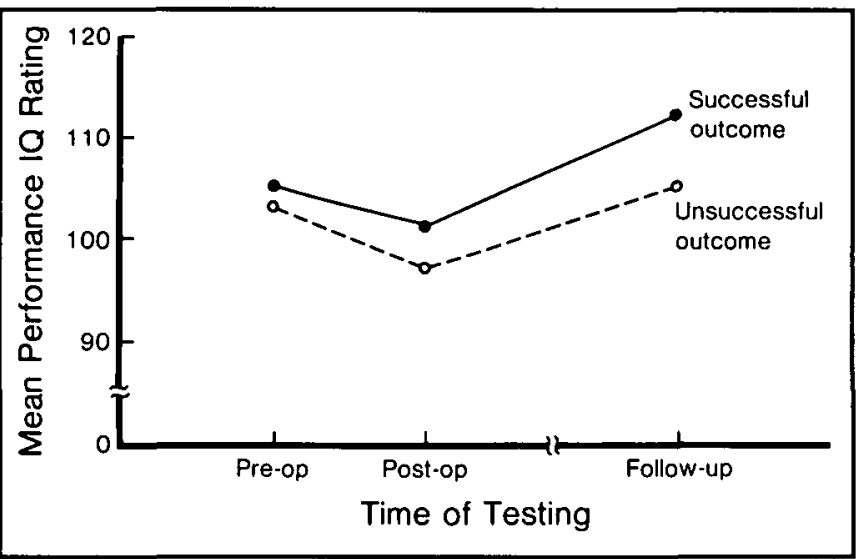

Figure I - Performance IQ. Two-way interaction between surgical outcome and time of testing showing the significant improvement demonstrated by the successful outcome group in follow-up testing, compared both to their preoperative level and to the unsuccessful outcome group.

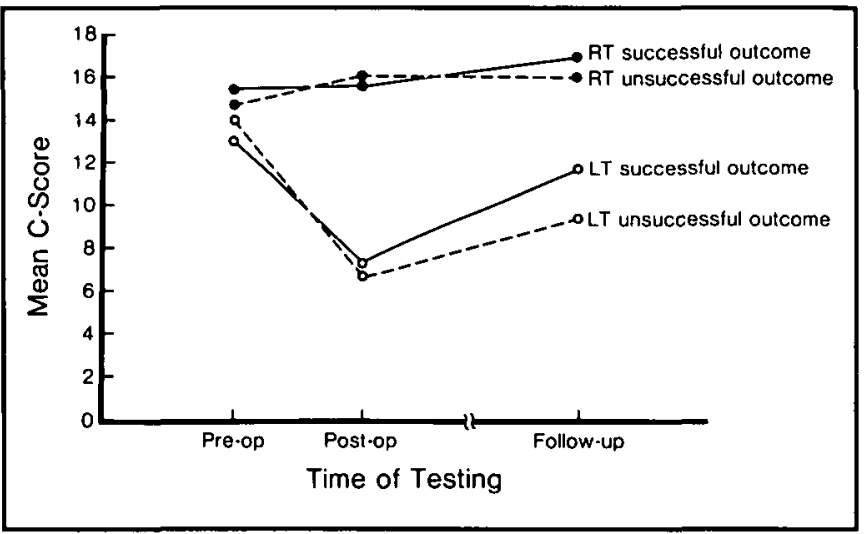

Figure 2 - Delayed verbal memory index. Three-way interaction between side of surgery, surgical outcome and time of testing. The patients in the left temporal-lobe groups show a significant loss postoperatively, however, subjects in the LT successful outcome group are significantly better in follow-up testing than the $L T$ unsuccessful outcome group.

\section{Discussion}

The statistical analyses confirm the main theme of the reports made by Drs. Rasmussen and Feindel (this supplement) in that there was no suggestion of a difference between the groups in surgical outcome as related to the extent of the encroachment upon the medial temporal region. The results also make clear that there were no significant effects brought about by size of lateral removal on surgical outcome. Some evidence indicating that smaller removals led to better surgical outcome was suggested by the finding that there were significantly more small removals on the left and an increased chance of being in the success group. A possible explanation for this finding may be that surgeons have slightly different criteria for selecting candidates for dominant hemisphere excisions, such that the lesions are more clearly focal.

Controversy exists as to whether seizure abolition or reduction of seizure frequency actually translates into changes in the patient's quality of life. ${ }^{6}$ The present study makes clear that patients who have successful surgical outcome, in terms of seizure reduction, perform significantly better, on a range of cognitive tests, than those patients who receive no benefit. ${ }^{18-20}$ In general, there are significant improvements in intelligence ratings and, although verbal memory losses are still present after left temporal lobectomy, it is nonetheless true that those patients who have successful surgery do significantly better, even on memory tests, than do those subjects in whom the seizures were not relieved. It is possible that some of the cognitive benefit observed in the successful group might be related to practice effects of repeated tests; however, both the successful group and the unsuccessful group performed the same tests. Alternatively, it could be suggested that the patients in the unsuccessful group are not improved cognitively because they are still on antiepileptic medication; however, many of the patients in the successful group are also taking medication and furthermore there are many tests on which there were no differences between the groups.

Finally it should be emphasized that there is persuasive evidence that extensive removal of the hippocampal formation (in addition to an anterior temporal-lobe excision) on the left or on the right can result in severe material-specific memory

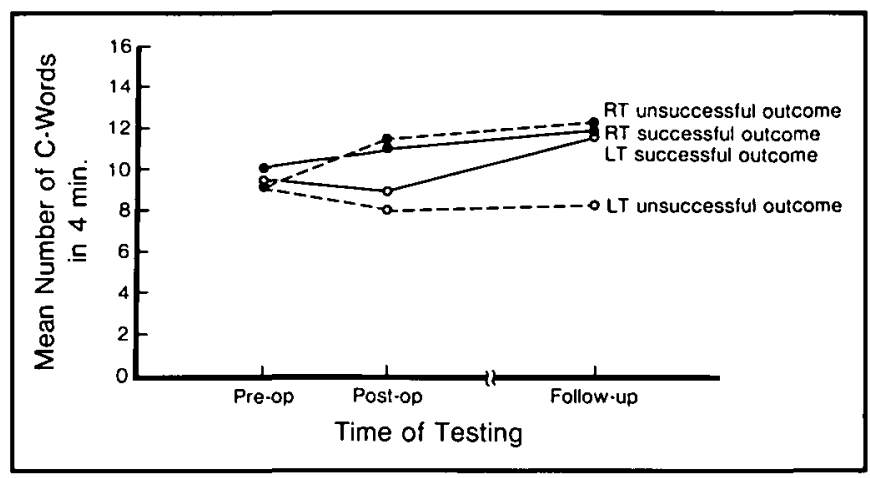

Figure 3 - Chicago Word Fluency ( $C$-words). Three-way interaction between side of surgery, surgical outcome and time of testing. In follow-up testing the LT successful outcome group show's significant improvement whereas the LT unsuccessful outcome group remains at preoperative testing level. 
deficits. ${ }^{2-14,21,22}$ Therefore, given that in the present series small hippocampal removals were as effective as large removals in reducing seizure frequency, encroachment upon the hippocampus should be kept to a minimum, unless there is preoperative evidence that the structure is non-functioning.

\section{ACKNOWLEDGEMENTS}

This research was supported by Grant MT 2624 to Brenda Milner. I am grateful to Dr. T. Rasmussen and Dr. W. Feindel for the opportunity to study their patients, and for providing detailed descriptions of the surgical removals as well as helpful comments. Most of the neuropsychological data were collected by M,K. Ajersch, M. Jones-Gotman, G. Leonard, E. McGovern, B. Milner, and L. Taylor. I am indebted to Brenda Milner for her careful reading of the manuscript.

\section{REFERENCES}

1. Penfield $W$. The radical treatment of traumatic epilepsy and its rationale. J Can Med Assoc 1930; 23: 189-197.

2. Hardiman O, Burke T, Phillips J, et al. Microdysgenesis in resected temporal neocortex: incidence and clinical significance in focal epilepsy. Neurology 1988; 38: 1041-1047.

3. Rasmussen $T$, Branch $C$. Temporal lobe epilepsy: Indications for and results of surgical therapy. J Postgrad Med 1962;31: 9-14.

4. Crandall PH. Postoperative Management and Criteria for Evaluation. In: Purpura DP, Penry JK, Walter RD, eds. Advances in Neurology. New York: Raven Press, 1975; 299-321.

5. Crandall PH, Rausch R, Engel J. Preoperative indicators for optimal surgical outcome for temporal-lobe epilepsy. In: Wieser HG, Elger CE, eds. Presurgical Evaluation of Epileptics. SpringerVerlag: Berlin Heidelberg, 1987; 325-334.

6. Dasheiff RM. Epilepsy surgery: is it an effective treatment? Ann Neurol 1989; 25: 506-510.

7. Dodrill CB, Wilkus RJ, Ojemann GA, et al. Multidisciplinary prediction of seizure relief from cortical resection surgery. Ann Neurol 1985; 20: 2-12.

8. Wada J, Rasmussen T. Intercarotid injection of sodium Amytal for the lateralization of cerebral speech dominance: experimenta and clinical observations. J Neurosurg 1960; 17: 166-282.
9. Milner B. Visual recognition and recall after right temporal-lobe excision in man. Neuropsychologia 1968; 6: 191-209.

10. Milner B. Brain mechanisms suggested by studies of temporal lobes. In: Darley FL, ed. Brain mechanisms underlying speech and language. New York: Grune and Stratton, 1976; 122-132.

11. Milner B. Memory. In: Weiskrantz L, ed. Analysis of behavioral change. New York: Harper \& Row, 1968: 328-375.

12. Corkin S. Tactually-guided maze learning in man: Effects of unilateral cortical excisions and bilateral hippocampal lesions. Neuropsychologia 1965; 3: 339-351.

13. Corsi PM. Human memory and the medial temporal regions of the brain. Unpublished doctoral dissertation, McGill University, Montreal, 1972.

14. Milner B. Visually-guided maze learning in man: Effects of bilateral hippocampal, bilateral frontal and unilateral cerebral lesions. Neuropsychologia $1965 ; 3: 317-338$.

15. Keppel G. Design and analysis: a researcher's handbook. New Jersey: Prentice-Hall, 1973.

16. Milner B. Psychological aspects of focal epilepsy and its neurosurgical management. In: Purpura DP, Penry JK, Walter RD, eds. Advances in Neurology. New York: Raven Press, 1975; 299-321.

17. Milner B. Complementary functional specializations of the human cerebral hemispheres. In: Levi-Montalcini R, ed. Nerve cells, Transmitters \& Behavior. Vatican City: Pontificiae Academiae Scientiarum Scripta Varia 45, 1980; 601-625.

18. Lieb JP, Rausch R, Engel J, et al. Changes in intelligence following temporal lobectomy: relationship to EEG activity, seizure relief, and pathology. Epilepsia 1983; 23: 1-13.

19. Rausch R. Psychological evaluation. In: Engel J, ed. Surgical Treatment of the Epilepsies. New York: Raven Press, 1987; 181195.

20. Rausch R, Crandall PH. Psychological status related to surgical control of temporal lobe seizures. Epilepsia; 1982; 23: 191-202.

21. Frisk V, Milner B. The role of the left hippocampal region in the acquisition and retention of story content. Neuropsychologia, in press.

22. Smith ML, Milner B. The role of the right hippocampus in the recall of spatial location. Neuropsychologia 1981; 19: 781-795. 